\title{
Market research into part time training: consumers' views and regional variations
}

\author{
CAROL A DAVIDSON, MICHAEL O'BRIEN, SUSAN H ROBERTS
}

\section{Introduction}

Although part time training has been available for 15 years it is widely acknowledged that the present scheme has its failings. ${ }^{1-5}$ The Department of Health and Social Security convened a working party to undertake a review and its interim recommendations including devolution of the schemes to the regions have been published. ${ }^{6}$

Most of the reports on part time training have been from the providers' standpoint ${ }^{7-11}$ though the views of the recipients in one region $^{11}$ and one specialty ${ }^{9}$ and those of various individuals ${ }^{2-4}$ are also recorded. To assess the experience of part time trainees in a broad range of specialties and various regions we sought the opinion of part time trainees in three regions from April to June 1984.

\section{Methods}

A questionnaire was sent to all part time trainees in the Northern, Yorkshire, and Trent regions. It asked for personal information, including reasons for joining the scheme, experiences of the scheme, opinions about it, and personal aspirations. A covering letter explained the objectives of the inquiry and guaranteed anonymity in the final analysis. A prepaid self addressed envelope was included. A single follow up inquiry was made to nonresponders within two months. The replies were collated by hand

\section{Results}

Initially 138 names and addresses were identified. Five were excluded, one had been a consultant for 17 months, three had moved, and one had just started and felt unable to answer. Replies were received from $111(83.5 \%)$ of the remaining 133 trainees. Although the numbers of trainees in the three regions varied widely (Northern 63, Yorkshire 28, and Trent 42), their response rates were similar (Northern $86 \%$, Yorkshire $79 \%$, Trent $83 \%$ ).

\section{PERSONAL DETAILS}

One reply was from a man. The age distribution of the respondents is shown in table I and their grades in table II. United

Darlington Health Authority, Darlington, Co Durham DL3 6HX

CAROL A DAVIDSON, $\mathrm{MB}, \mathrm{CHB}$, registrar in community medicine

Northern Regional Health Authority, Newcastle upon Tyne NE6 4PY

MICHAEL O'BRIEN, MB, FFCM, specialist in community medicine

North Tyneside Health Authority, North Shields, Tyne and Wear NE29 8AU SUSAN H ROBERTS, MSC, FRCP, consultant physician

Correspondence to: Dr Roberts, Preston Hospital, North Shields, Tyne and Wear NE29 0LR.
Kingdom graduates accounted for $84 \%$ of respondents. There was no appreciable difference in the proportion of United Kingdom and overseas graduates between the three regions.

Just over half the trainees (57) were in four specialties, psychiatry (23), anaesthetics (16), paediatrics (10), and obstetrics and gynaecology (eight, one region only). The remaining 54 were distributed throughout 18 specialties, and no other individual specialty accounted for more than six trainees.

\begin{tabular}{lccc} 
TABLE I-Age distribution of part time trainees \\
\hline \multicolumn{4}{c}{ Regional health authority } \\
\cline { 2 - 4 } & $\begin{array}{c}\text { Northern } \\
(\%)\end{array}$ & $\begin{array}{c}\text { Yorkshire } \\
(\%)\end{array}$ & $\begin{array}{c}\text { Trent } \\
(\%)\end{array}$ \\
\hline Age group & 11 & & 6 \\
\hline $25-29$ & 35 & 23 & 34 \\
$30-34$ & 39 & 54 & 34 \\
$35-39$ & 15 & 23 & 26 \\
Over 40 & & &
\end{tabular}

TABLE II-Grade distribution of part time trainees

\begin{tabular}{lccc}
\hline & \multicolumn{3}{c}{ Regional health authority } \\
\cline { 2 - 4 } Grade & Northern & Yorkshire & Trent \\
\hline Senior house officer & 8 & & 8 \\
Registrar & 25 & 10 & 10 \\
Senior registrar & 19 & 12 & 14 \\
Clinical assistant & 2 & & 3 \\
\hline
\end{tabular}

A substantial majority of the respondents had additional qualifications (table III). An average of $59 \%$ of trainees had the membership or fellowship of a royal college (Northern $50 \%$, Yorkshire $77 \%$, Trent $49 \%$ ), and many trainees had obtained their higher qualification in the course of part time training (Northern $28 \%$, Yorkshire $36 \%$, Trent $46 \%$ ). A large proportion were still intending to take further examinations or submit theses for higher degrees. Only a few did not intend to obtain higher qualification.

Most of the trainees gave a commitment to children as the main reason for wishing to train part time (Northern $80 \%$, Yorkshire $95 \%$, Trent 94\%). Geographical limitation was also cited (Northern

TABLE III-Part time trainees and higher qualifications

\begin{tabular}{lccc}
\hline & \multicolumn{3}{c}{ Regional health authority } \\
\cline { 2 - 4 } $\begin{array}{l}\text { Higher } \\
\text { qualifications }\end{array}$ & $\begin{array}{c}\text { Northern } \\
(\%)\end{array}$ & $\begin{array}{c}\text { Yorkshire } \\
(\%)\end{array}$ & $\begin{array}{c}\text { Trent } \\
(\%)\end{array}$ \\
\hline Total with higher qualifications & 69 & 91 & 66 \\
Higher qualifications before part time training & 41 & 54 & 20 \\
Intending to obtain more qualifications & 59 & 43 & 49 \\
Not intending to take higher qualifications & 7 & & 14
\end{tabular}


$26 \%$, Yorkshire $27 \%$, Trent $3 \%$ ). For some this was their main reason, but for others it was supplementary to their commitment to children. Other domestic commitments were mentioned (Northern $13 \%$, Yorkshire $4.5 \%$, Trent $11 \%$ ). Only five (three in the Northern region and two in Trent) referred to disability or ill health. Four (three in the Northern region and one in Trent) stated with disarming honesty that they had opted for part time training because they could not get a full time post.

Table IV illustrates the average duration of part time training by grade in posts held at the time of the inquiry and previously.

TABLE IV-Average time (months) spent in part time training

\begin{tabular}{lccc}
\hline & \multicolumn{3}{c}{ Regional health authority } \\
\cline { 2 - 4 } & Northern & Yorkshire & Trent \\
\hline Previous posts: & & & \\
$\quad$ Senior house officer & 11 & 19 & 36 \\
$\quad$ Registrar & 28 & 50 & 51 \\
$\quad$ Senior registrar & & & 36 \\
$\quad$ Clinical assistant & & & 60 \\
Current posts: & 10 & & 20 \\
$\quad$ Senior house officer & 33 & 21 & 29 \\
Registrar & 32 & 29 & 32 \\
Senior registrar & 120 & & 38 \\
$\quad$ Clinical assistant & & & \\
\hline
\end{tabular}

TABLE V-Length of time taken to arrange part time training posts

\begin{tabular}{lccc}
\hline & \multicolumn{3}{c}{ Regional health authority } \\
\cline { 2 - 4 } \multicolumn{1}{c}{ Time } & $\begin{array}{c}\text { Northern } \\
(\%)\end{array}$ & $\begin{array}{c}\text { Yorkshire } \\
(\%)\end{array}$ & $\begin{array}{c}\text { Trent } \\
(\%)\end{array}$ \\
\hline Less than 3 months & 36 & 24 & 17 \\
Less than 6 months & 24 & 33 & 26 \\
Less than 9 months & 18 & 14 & 11 \\
Less than 1 year & 12 & 24 & 29 \\
More than 1 year & 10 & 5 & 17 \\
\hline
\end{tabular}

\section{EXPERIENCE OF THE SCHEME}

Trainees first learnt about the possibility of part time training from three sources: individual consultants (Northern 59\%, Yorkshire 33\%, Trent 54\%); official literature (Northern $24 \%$, Yorkshire $19 \%$, Trent $40 \%$ ); and other trainees (Northern 19\%, Yorkshire $48 \%$, Trent $17 \%$ ). Some had information from more than one source including regional health authority staff or representatives of the Medical Women's Federation.

A substantial minority thought that they had not received any formal counselling on the subject of part time training (Northern $37 \%$, Yorkshire $36 \%$, Trent $26 \%$ ). Barely more than half had job descriptions (Northern 57\%, Yorkshire 55\%, Trent 57\%).

About one third of trainees believed that there was no monitoring of their progress (Northern $37 \%$, Yorkshire 32\%, Trent 37\%). The others reported that it was largely in the hands of the individual consultant responsible for their training (Northern $85 \%$, Yorkshire $40 \%$, Trent $81 \%$ ) though a few mentioned district clinical tutors and royal college and faculty regional advisors.

\section{OPINIONS ABOUT THE SCHEME}

In the Northern region $63 \%$ thought that the personal post had been arranged quickly. The percentages for Yorkshire and Trent were $50 \%$ and $40 \%$ respectively. The actual times taken to arrange the post in the three regions are shown in table V. Delay was attributed to "administration" by $80 \%$ of respondents from each region. A few had had difficulty in finding a clinical unit in which to train or difficulty in getting educational approval from the relevant royal college or joint training committee (Northern $32 \%$, Yorkshire
$18 \%$, Trent 19\%). In Yorkshire 18\% ascribed the delay to lack of finance.

Most trainees thought that time for study was either adequate or generous (Northern 83\%, Yorkshire 91\%, Trent 81\%). Opportunity to undertake research varied (Northern $73 \%$, Yorkshire $50 \%$, Trent $70 \%$ ) but was not related to the percentage of senior registrars in each scheme.

Trainees varied widely in the distance that they were prepared to travel to receive their training (over 30 miles for $22 \%$ in the Northern region) and in their projected need to move outside their current region before the end of their training (Northern $9 \%$, Yorkshire $9 \cdot 5 \%$, Trent $26 \%$ ).

A majority of respondents thought that their training was adequate to enable them to compete for a post in the next higher grade (Northern $61 \%$, Yorkshire $64 \%$, and Trent $71 \%$ ). More than half the remainder thought that the training was inadequate and the rest simply did not know.

Table VI illustrates the stated long term career intentions of the respondents. Answering questions about the "ideal" future, a majority wanted to work full time at some stage though a large minority (Northern $39 \%$, Yorkshire $32 \%$, Trent $46 \%$ ) opted for a part time career long term or for a period before being full time (Northern 19\%, Yorkshire 14\%, Trent 14\%).

TABLE VI-Long term career intentions of part time trainees

\begin{tabular}{lccc}
\hline & \multicolumn{3}{c}{ Regional health authority } \\
\cline { 2 - 4 } \multicolumn{1}{c}{ Career intention } & $\begin{array}{c}\text { Northern } \\
(\%)\end{array}$ & $\begin{array}{c}\text { Yorkshire } \\
(\%)\end{array}$ & $\begin{array}{c}\text { Trent } \\
(\%)\end{array}$ \\
\hline NHS consultant & 69 & 86 & 69 \\
$\begin{array}{l}\text { Overseas post } \\
\text { General practitioner }\end{array}$ & 7 & & 3 \\
$\quad \begin{array}{l}\text { Subconsultant grade: } \\
\quad \text { Unspecified }\end{array}$ & 4 & & 11 \\
$\quad$ Associate specialist & 15 & 14 & 8 \\
$\quad$ Clinical assistant & 3 & & 9 \\
Clinical medical officer & 2 & & \\
\hline
\end{tabular}

Trainees were given the opportunity to make additional comments about the scheme. They all confirmed views expressed elsewhere..$^{2-4}$ These included difficulties in gaining acceptance as part of a clinical unit, gaining acceptance by full time colleagues, getting adequate on call experience, and persuading interview panels that they had not taken an easy option by undertaking part time training.

\section{Discussion}

Many features emerging from this survey are encouraging. Most trainees obtained higher qualifications in the course of their personal part time training or intended to take further examinations or both. A large majority regarded themselves as training for National Health Service consultant posts and were prepared to prolong their training substantially and travel fair distances to pursue this aim.

Some of the findings are important for local organisers of the posts. Those without job descriptions should have them provided; arrangements for monitoring the progress of trainees should be clarified and publicised; and opportunities for research should be available where appropriate. The educational content of training needs to be satisfactory, not only to the relevant college or faculty on theoretical grounds but must be seen to be so in practice to give the trainees the self confidence to compete for career posts. The credibility of the training in the eyes of others, particularly those who will be concerned with the appointment of trainees to their ultimate career post, is also important. These aspects, however, may be resolved only by incorporating part time training into established career grades.

The manpower implications of the survey have positive features. Despite the clear demand for part time consultant posts, largely 
unmet at present, those surveyed were willing to be flexible when considering the future. The numbers in part time training are small, nationally less than $9 \%$. Applicants at senior registrar level have not increased dramatically in the period 1981-2 to 1983-4 inclusive, despite an increase in the number of women graduates entering this stage in their training. Most part timers still opt for a small range of specialties.

Ill health and disability play so little part in doctors' requirements for part time training that this small group could be excluded from the scheme entirely and their needs left to local ad hoc arrangements.

It is usually presumed that the posts that part timers find themselves in are determined by their own needs and choices. Quite unexpectedly this survey shows three distinct approaches in the three regions (tables III, IV), suggesting that other factors related to the employing authority may be exerting powerful effects on the distribution and type of part time training available. Yorkshire has small numbers of trainees solely in the registrar and senior registrar grades but with $86 \%$ aiming at NHS consultant appointments and the highest percentage expecting to work full time. Ninety five per cent state a commitment to children as their major reason for part time training. Yorkshire trainees have the highest percentage with postgraduate qualifications, many of which were obtained before they joined the scheme. They all intend to obtain qualifications.

The Trent region also concentrates on registrar and senior registrar posts but employs several senior house officers and clinical assistants - the latter not officially a training grade-who have spent longer in previous part time work and longer in their current posts than in the other regions. They have fewer higher qualifications than those in either of the other regions though many were obtained while working part time. They have the highest number who do not intend to sit for them at all. Most have a commitment to young children but also declare other reasons for part time training. Sixty nine per cent are aiming at consultant posts, $17 \%$ at a subconsultant role, and four are part time general practitioner trainees. These features show quite distinct approaches to part time training in the two regions, which, though influenced by local demand and geography, almost certainly reflect varying and unspoken policy differences. Yorkshire seems to interpret the guidelines most rigidly, defining domestic commitment as solely related to child care and selecting a small number of the best qualified, highly motivated women already committed to a specialty for higher training. The results from Trent are similar to those described five years ago from Oxford. "In addition to the group identified in Yorkshire, there are several women previously out of mainstream training with slightly lower expectations who nevertheless value their training and the benefit that it will exert on their eventual service contribution.

The Northern region is interpreting the need for part time training in a third and broader way, more in keeping with the spirit of the preamble to the current guidelines and most recent proposals. ${ }^{612}$ With the exception of one clinical assistant older women have moved out of the scheme, which now has its greatest number in the registrar grade with some senior house officers. Trainees are moving through the grades at a reasonable rate, have a large number of higher qualifications, but also intend to take more, leaving only $7 \%$ who do not intend to obtain any higher qualifications. Sixty nine per cent are aiming at consultant posts with $22 \%$ looking to a subconsultant appointment. Though the actual time taken to set up the scheme was similar in all regions, more trainees in the Northern region thought that it had been arranged quickly and were aware that factors other than commitment to child care were acceptable as reasons for needing part time work. Other domestic commitments were quoted; as was the inability to find a full time post, which for some reflects the geographical constraints of this large region.

\section{Conclusions}

Current proposals for part time training from mid-1985 envisage devolution of all aspects of the scheme to the regions. Regional variations in the ease of arranging appointments have been recognised for a long time. The present survey shows that there are distinctly different approaches at least in three regions. Local demand and geography must play some part in this and attitudes to the employment of women doctors as a whole may be a factor, though the correlation is by no means clear. Economic factors are sometimes the stated reason and were mentioned as a reason for delay in Yorkshire. It is understood that in the North East Thames region a decision has been made to phase out all part time appointments because of an expressed belief that women are already succeeding in full time posts quite satisfactorily.

These differences are not only important to the individuals concerned but may influence the development of the scheme in the future. Interestingly, Yorkshire has the highest percentage of trainees in the conventional specialties of psychiatry and anaesthetics, with both Trent and the Northern region offering a much wider range of specialties. The Northern region, with its more flexible approach, has eight trainees in obstetrics and gynaecology, the highest number in the entire country and a particularly important specialty for women to train in.

It is unlikely that a region will change its approach dramatically when the scheme is devolved without some specific central guidelines. Regional variations must be monitored and analysed nationally and a central review initiated to prevent the least motivated regions from slipping behind and to ensure that the broad intentions of the scheme are fulfilled more widely by maintaining a flexible and innovative approach.

We should like to thank Dr E D Mackie, specialist in community medicine, Yorkshire Regional Health Authority; Dr G B Todd, formerly specialist in community medicine, Trent Regional Health Authority; all the part time trainees who responded to our inquiry; and Mrs Irene Macdonald and Miss Heather Bruce for their secretarial help.

\section{References}

I Varnam M. Part-time training: is it viable? Br Med $\mathcal{f} 1982 ; 285: 1016-7$.

2 Jones RAK. Part time training in acute medical specialties. Br Med $\mathcal{J} 1983 ; 287: 1473$.

Lewis H. Part time training in acute medical specialties. Br Med f 1983;287:1473.

Rees L, van Someren V. Personal view. Br Med f 1984;289:827.

Roberts S. An open letter to the chairman of the working party on part time postgraduate training. BrMed f 1984;289:933-5.

6 Anonymous. Part time senior registrar training. Br Med f 1985;290:408. Med f 1981;283:1371-3.

Jed $1981,283.1371-3$.

Public Health 1984;98:134-8.

. Burke $C$, Black NA. Part time senior registrars, registrars and senior house officers in general medicine and its sub-specialties. A report to the Royal College of Physicians. Br Med $\mathrm{J}$ 1983;287:1040-4

10 Burke CW. Part time training in general medical specialties: is it any use? $\mathrm{Br}$ Med $\mathrm{f}$ 1983;287:1037-9.

11 Swerdlow AJ, McNeilly RH, Rue ER. Women doctors in training: problems and progress. $\mathrm{Br}$ Med f 1980;281:754-8.

12 Department of Health and Social Security. Opportunities for part-time training in the NHS for doctors and dentists with domestic commitments, disability or ill-health. London: DHSS, 1979. (PM $(79) 3$

(Accepted 15 October 1985)

\section{THIRTY YEARS AGO}

The bad handwriting of many doctors was criticized at a meeting of the Northern Ireland General Health Services Board on June 29, and it was decided to warn 12 of the worst offenders that their writing must improve.

Mr. G. D. Stewart (secretary) said that there had been an apparent deterioration in the standards of doctors' handwriting. It had generally been taken for granted that a number of older doctors were very indifferent writers, but it now seemed that the younger men were falling into the same habit. The Board was not so much concerned about the signatures, as the prescriptions were marked with numbers which enabled them to identify the doctor who had issued them. Mr. J. P. Duff (chairman) said that some time ago the writing of prescriptions was so bad in certain cases that the doctors concerned were informed that the Board would refuse to pay for prescriptions unless their writing improved. There had been some improvement after that, he added. (British Medical Fournal 1955,ii:11.) 